\title{
Positive Youth Development: Interactions Between Healthy Lifestyle Behaviours and Psychosocial Variables
}

\author{
Margarida Gaspar de Matos ${ }^{1,2,3}$,Teresa Santos ${ }^{1,2,3}$, Marta Reis ${ }^{1,2}$ \& Adilson Marques ${ }^{1,2}$ \\ ${ }^{1}$ Faculdade de Motricidade Humana (Equipa Aventura Social), Universidade de Lisboa, Portugal \\ ${ }^{2}$ Instituto de Saúde Ambiental, Faculdade de Medicina, Universidade de Lisboa, Portugal \\ ${ }^{3}$ William James Center for Research, ISPA - Instituto Universitário, Lisboa, Portugal \\ Correspondence: Margarida Gaspar de Matos, FMH/Universidade de Lisboa, Estrada da Costa 1495-688 Cruz \\ Quebrada, Portugal. Tel: 351-21-414-9152. E-mail: mmatos@fmh.ulisboa.pt
}

Received: January 16, 2018 Accepted: February 26, 2018 Online Published: March 12, 2018

doi:10.5539/gjhs.v10n4p68 URL: https://doi.org/10.5539/gjhs.v10n4p68

\begin{abstract}
The Positive Youth Development - PYD concept emphasised the importance of strengthening developmental assets in youth's networks and contexts. This paper examines the correlation between PYD, healthy lifestyle behaviours and psychosocial variables (self-regulation, resilience, and anxiety); and the impact of PYD and psychosocial variables on healthy lifestyle behaviours. 2700 youths $(73.3 \%$ girls; mean age $21.3 \pm 2.79$ years) were included. Results showed that all variables mostly had significantly correlational associations. Specifically, the linear regression model evidenced that the promotion of PYD and self-regulation, along with the reduction of anxiety can be relevant for improving healthy lifestyle behaviours. Such results suggest a dynamic interdependence between all the present variables, reinforcing the need to study positive indicators for youth development. Having more knowledge in this area can help health professionals, educators, and policy-makers, in order to better plan interventions/policies and to improve an integral healthy perspective for youths, based on interdisciplinary and transdisciplinary work.
\end{abstract}

Keywords: Five Cs, healthy lifestyle behaviours, Positive Youth Development (PYD), psychosocial variables, youths

\section{Introduction}

Youth studies have been characterized by a "deficit perspective", mainly based on risk and problem behaviours, which influenced policies, research and practice. This was the outline approach during the past century and the concept of positive development was basically defined on the absence or decrease of problems (Geldhof et al., 2014). Over the past two decades, the study of positive indicators significantly increased (Lippman, Moore, \& McIntosh, 2011) and it was largely recognized that youth programs and interventions would have limited impact, if they would only focus on risks and vulnerabilities. Thus, the interest in preventing youth problems and promoting healthy youth development led to the implementation of strength-based approaches, which aimed to be empowering and effective in diverse contexts (Benson, Scales, Hamilton, \& Sesma, 2006). Such approaches were based on several theoretical frameworks (Small \& Memmo, 2004), as for example the Positive Youth Development-PYD.

PYD highlighted the importance of strengthening internal and external developmental assets comprised in the social ecology of youth's networks and opportunities (Catalano, Berglund, Ryan, Lonczak, \& Hawkins, 2004; Small \& Memmo, 2004). Within this approach, positive indicators such as the Search Institute's Developmental Assets model('s?) (Benson, Leffert, Scales, \& Blyth, 1998) and the Five Cs model of PYD (Lerner et al., 2013; Lerner et al., 2011) have been widely studied. The Search Institute's framework identified 40 relevant developmental assets (Benson et al., 1998), comprised in two blocks, respectively: 1) external assets and 2) internal assets. The Five Cs (Lerner et al., 2013; Lerner et al., 2011) include the following Cs: Competence, Confidence, Character, Connection and Caring, in agreement with empirical evidence (Busseri \& Rose-Krasnor, 2009; Lerner et al., 2005; Lerner et al., 2011).

Literature states/argues/hypothesizes that when young people experience developmental assets in line with human 
and structural resources in its context, positive development is facilitated. Accordingly, an adaptive developmental regulation process takes place where young people are able to contribute to the development of both self and society (Lerner et al., 2005; Erickson, 1982).

Facing this theoretical background and taking into account that there is a lack of studies attempting to capture the dynamic relation between youth and their context (Conway, Heary, \& Hogan, 2015), a better understanding is needed on the association between PYD, healthy behaviours and psychosocial variables that can predict health outcomes. Psychosocial factors have been already widely referred in literature related to health outcomes (Kojima et al., 2009). In addition, behaviours are also crucial determinants to improve health outcomes (CDC, 2009; ECDA, 2012; WHO, 2013a) and the most important ones are physical activity, healthy diet, moderate alcohol consumption, not smoking (Brownson, Remington, \& Wegner, 2010; WHO, 2005, 2014) and sleeping hours (Cable, Chandola, Aida, Sekine, \& Netuveli, 2017; Grandner, Hale, Moore, \& Patel, 2010). A healthy lifestyle should be a combination of all these behaviours (Loef \& Walach, 2012) and literature has shown that health/risk behaviours tend to cluster together (Suris et al., 2008; Rhee, Yun \& Khang, 2007).

Thus, the present study aims to examine 1) the correlation between PYD, a composite of healthy lifestyle behaviours and psychosocial variables (self-regulation, resilience and anxiety), and 2) the impact of PYD and psychosocial variables in healthy lifestyle behaviours.

\section{Materials and Methods}

\subsection{Study Design, Participants and Procedure}

The present research was conducted in the BePositive project (Matos, Santos \& Reis, 2017), a cross-sectional study and a part of the local national survey Health Behaviour in School-aged Children (HBSC/WHO) (Matos \& Equipa Aventura Social, 2000-2014) extended to Portuguese Universities (HBSC/JUnP). The HBSC/JUnP are in line with principles of the Declaration of Helsinki (WMA, 2008) and was approved by the Ethics Commission of the Medicine Academic Center of Lisbon of the Faculty of Medicine, University of Lisbon.

The BePositive study is a result of the Portuguese partnership within the Positive Youth Development cross-national project (http://www.uib.no/en/rg/sipa/pydcrossnational) that aims to: 1) examine the extent to which developmental (internal and external) assets are accessible to young people in different national contexts; 2) understand how these assets can be related to positive youth outcomes, such as the "5 Cs" of PYD (i.e., confidence, competence, character, caring and connection) and thriving indictors (e.g., school success, values diversity, resists danger and exhibit leadership); 3) highlight how positive outcomes are associated to young people's contribution to the development of the self and to the involving society.

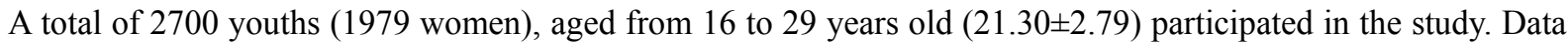
collection was performed throughout an online survey, using the Limesurvey platform. Prior to data collection, youths were informed about the purpose of the study and informed consents were obtained. Informed consent from parents was sought as well for the youths below 18 years old. Youths were assured confidentiality of their responses to the questionnaire and during the handling of the data.

\subsection{Measures and Instruments}

All the next measures were obtained in a single self-reported questionnaire, composed of several parts that took approximately 45 minutes to respond. The first one included the instructions and informed consent. The second part included the socio--demographic characterization, namely age, gender, geographic region, nationality, and education level. Finally, the third part contained questions related to the youth himself and others, comprising the assessment of Positive Youth Development-PYD (Bowers et al., 2010; Geldhof et al., 2014; Jelicic, Bobek, Phelps, Lerner, \& Lerner, 2007) and psychosocial variables such as Resilience-RES (Scale Healthy Kids Resilience Assessment Module) (Constantine \& Benard, 2001; Constantine, Benard, \& Diaz, 1999; Martins, 2007; Simões et al., 2012; Simões, Matos \& Morgan, 2015), Self-regulation-SR (Scale Adolescent Self-Regulatory Inventory-ASRI) (Dias, Castillo, \& Moilanen, 2014; Moilanen, 2007) and Anxiety-STAI-T (State-Trait Anxiety Inventory) (Silva \& Spielberger, 2007; Spielberger, Gorsuch, \& Lushene, 1970).

Detailed information on these measures and instruments is described in Table 1. 
Table 1. Measures and Instruments

\begin{tabular}{|c|c|c|c|}
\hline \multicolumn{4}{|c|}{ Sociodemographic Variables } \\
\hline \multicolumn{3}{|l|}{ Age } & Mín: 16 - Máx: 29 (Years Old) \\
\hline \multicolumn{3}{|l|}{ Gender } & $1=$ Boy; $2=$ Girl \\
\hline \multicolumn{3}{|l|}{ Nationality } & $1=$ Portuguese $; 2=$ Others \\
\hline \multicolumn{3}{|l|}{ Educational Level } & $1=$ Secondary; $2=$ Graduate; $3=$ Master \\
\hline \multicolumn{3}{|c|}{ Socio Economic Status - SES } & 1=Low; 2=Middle; 3=High \\
\hline \multicolumn{4}{|l|}{ Psychosocial Variables } \\
\hline Name & $\begin{array}{l}\text { Psychosocial } \\
\text { Measure }\end{array}$ & $\begin{array}{l}\text { Abbreviation } \\
\text { (in this study) }\end{array}$ & Short Description \\
\hline $\begin{array}{l}\text { Positive Youth } \\
\text { Development-PYD, } \\
\text { Short Form, } \\
\text { Portuguese Reduced } \\
\text { Version } \\
\text { (Bowers et al., 2010; } \\
\text { Geldhof et al., 2014; } \\
\text { Jelicic, Bobek, Phelps, } \\
\text { Lerner, \& Lerner, } \\
\text { 2007; Lerner et al., } \\
\text { 2005) }\end{array}$ & $\begin{array}{l}\text { Positive Youth } \\
\text { Development } \\
\text { (5 Cs: } \\
\text { Confidence, } \\
\text { Competence, } \\
\text { Connection, } \\
\text { Caring and } \\
\text { Character) }\end{array}$ & PYD-SF-PT & $\begin{array}{l}\text { - The original version of PYD scale was developed } \\
\text { using data from the 4-H Study in its different waves, } \\
\text { which proposed and tested a higher-order measure of } \\
\text { PYD, consisting of a five first-order latent constructs, } \\
\text { each representing one of the Five Cs of PYD; } \\
\text { The } 78 \text { items from the original scale were drawn and } \\
\text { adapted from several questionnaires. More recently, a } \\
\text { shorter version of this scale (with } 34 \text { items) was } \\
\text { developed - the Positive Youth Development Short } \\
\text { Form (PYD-SF); } \\
\text { In the present study, the PYD-SF was translated from } \\
\text { the original English version into Portuguese language } \\
\text { (and back translation), and a reduced version ( } 24 \\
\text { items) showing reasonable psychometric properties } \\
\text { was used; } \\
\text { Higher scores indicate higher levels of PYD; } \\
\alpha=.0 .83 \text { (in the present study) }\end{array}$ \\
\hline $\begin{array}{l}\text { Healthy Kids } \\
\text { Resilience Assessment } \\
\text { Module } \\
\text { (Constantine \& } \\
\text { Benard, 2001; } \\
\text { Constantine, Benard, \& } \\
\text { Diaz, 1999; Martins, } \\
\text { 2007; Simões et al., } \\
\text { 2012; Simões, Matos \& } \\
\text { Morgan, 2015) }\end{array}$ & $\begin{array}{l}\text { Resilience } \\
\text { ( } 2 \text { dimensions: } \\
\text { external and } \\
\text { internal } \\
\text { resources). }\end{array}$ & RES & $\begin{array}{l}\text { - } 18 \text { items answered on a 4-point scale; } \\
\text { Ranges from } 18 \text { to } 72 ; \\
\text { - } \quad \text { Higher scores indicate higher levels of competences, } \\
\text { protection and resilience to adversity; } \\
\text { In this study it was used the Portuguese Version of the } \\
\text { questionnaire and it was only considered the internal } \\
\text { resources dimension; } \\
\quad \alpha=.0 .84 \text { (in the present study). }\end{array}$ \\
\hline $\begin{array}{l}\text { Adolescent } \\
\text { Self-Regulatory } \\
\text { Inventory-ASRI } \\
\text { (Dias, Castillo, \& } \\
\text { Moilanen, 2014; } \\
\text { Moilanen, 2007) }\end{array}$ & $\begin{array}{l}\text { Self-regulation } \\
\text { (2 dimensions: } \\
\text { Short } \\
\text { term-SR-ST and } \\
\text { Long } \\
\text { term-SR-LT). }\end{array}$ & SR & $\begin{array}{l}\text { - } 36 \text { items answered on a 5-point Likert scale; } \\
\text { - } \quad \text { Ranges from } 36 \text { to } 180 ; \\
\text { Higher values indicate better competences of } \\
\text { self-regulation; } \\
\text { - } \quad \text { In this study the instrument was translated from the } \\
\text { original English version into Portuguese language. It } \\
\text { was then revised by a group of specialized experts } \\
\text { within this field and a pre-test with a group of } \\
\text { students was conducted in schools. } \\
\text { - } \alpha=.0 .90 \text { (in the present study). }\end{array}$ \\
\hline
\end{tabular}




\begin{tabular}{|c|c|c|}
\hline $\begin{array}{l}\text { State-Trait Anxiety } \\
\text { Inventory (STAI-T) } \\
\text { (Silva \& Spielberger, } \\
\text { 2007; Spielberger, } \\
\text { Gorsuch \& Lushene, } \\
\text { 1970) }\end{array}$ & $\begin{array}{l}\text { Anxiety } \\
\text { (2 dimensions: } \\
\text { state-anxiety and } \\
\text { trait-anxiety). }\end{array}$ & $\begin{array}{l}\text { Two subscales: Y-1 (state-anxiety) and Y-2 } \\
\text { (trait-anxiety), each one comprising } 20 \text { items. } \\
\text { State-anxiety reflects answers related to feeling } \\
\text { anxiety in a specific moment, whereas trait-anxiety to } \\
\text { usually feel anxiety. } \\
\text { - } 40 \text { items answered on a 5-point scale; } \\
\text { - } \quad \text { In this study it was used the Portuguese Version of the } \\
\text { questionnaire and only the items of the Trait } \\
\text { dimension were included; } \\
\text { - } \quad \text { Higher scores indicate higher level of anxiety; } \\
\text { - } \alpha=.58 \text { (in the present study). }\end{array}$ \\
\hline
\end{tabular}

\subsection{Data Analysis}

All data from Limesurvey was transferred to an electronic data file, all variables were checked for data inaccuracy by running SPSS frequencies; and afterwards, an analysis on missing values was conducted. Descriptive analysis (means, standard deviation and percentage) were used to characterize the sample. All data were tested for normality prior to any analyses using Kolmogorov-Smirnov tests, as well as Levene's test for the homogeneity of the variance. Psychometric analyses were also performed through an analysis of the coefficient of internal consistency (Cronbach's alpha). Pearson correlation and linear regression were performed to evaluate significant differences in the analysed variables among the total group of youths. All statistical analyses were completed using the SPSS 24.0 (Statistical Package for Social Sciences) and the significance level was set at $\mathrm{p}<0.05$.

The composite score of healthy lifestyle index was created using the combination of seven behaviour and participants scored one point for achieving each of the following lifestyle categories: a) having breakfast 7 days/week; b) sleeping hours $\geq 7$ hours; c) not smoking; d) not consuming drugs; e) not getting drunk; f) not having intense worries; g) not being bored at school. Thus, the healthy lifestyle index ranged from 0 to 7 and only a score of 7 can represent a healthy lifestyle.

\section{Results}

The 2700 included adolescents ( $26.7 \%$ males; $73.3 \%$ female) had a mean age of 21.3 years $(S D=2.79)$. Most of the participants had Portuguese nationality (96.8\%), were born in Lisbon $(33.4 \%)$, were living in an urban area (46.4\%), were graduate students (63.5\%) and had a middle socioeconomic status (SES) level (67.7\%).

The socio-demographic variables, the psychosocial variables, the Healthy Lifestyle Index and the PYD-SF-PT included in the present study for the total group of youths are presented in Table 2.

Table 2. Socio-demographic characteristics, psychosocial variables, healthy lifestyle index, PYD-SF-PT and the its $5 \mathrm{C} /$ subscale dimensions for the total group of youth

\begin{tabular}{ll}
\hline & Total Group (N=2700) \\
\hline Socio-demographic characteristics & \\
\hline Age (years) (M \pm SD) & $21.30 \pm 2.79$ \\
Gender (\%) & 26.7 \\
Male & 73.3 \\
Female & \\
Socio-Economic Status-SES (\%) & 13.1 \\
Low & 67.7 \\
Medium & 19.2 \\
High & \\
\hline
\end{tabular}




\begin{tabular}{ll}
\hline Psychosocial variables $(\mathbf{M} \pm$ SD) & \\
\hline SR & $143.80 \pm 18.18$ \\
RES & $55.58 \pm 8.034$ \\
STAI-T & $45.24 \pm 9.23$ \\
\hline Healthy Lifestyle Index $*$ (M \pm SD) $^{1}$ & \\
\hline HLIndex $^{1}$ Mín. $=0 ;$ Máx. $=7$ ) & $4.45 \pm 1.48$ \\
\hline PYD-SF-PT and its dimensions $(\mathbf{M} \pm$ SD) & $14.35 \pm 3.42$ \\
\hline PYD-CONFIDENCE & $14.56 \pm 3.33$ \\
PYD-COMPETENCE & $13.57 \pm 2.91$ \\
PYD-CONNECTION & $16.73 \pm 2.50$ \\
PYD.CARING & $16.26 \pm 2.78$ \\
PYD-CHARACTER & $75.47 \pm 9.21$ \\
PYD-TOTAL SCORE & \\
\hline
\end{tabular}

PYD-SF-PT: Positive Youth Development-Short Form, Portuguese reduced Version; RES: Resilience; SR: Self-regulation; STAI-T: State-Trait Anxiety Inventory, Trait.

*The Healthy lifestyle Index was created using the combination of seven behaviour and participants scored one point for achieving each of the following lifestyle categories: a) having breakfast 7 days/week; b) sleeping hours $\geq 7$ hours; c) not smoking; d) not consuming drugs; e) not getting drunk; f) not having intense worries; g) not being bored at school.

${ }^{1}$ Number of behaviours reported.

The correlations of PYD-SF-PT (total score) and its dimensions with the psychosocial variables and the Healthy Lifestyle Index are shown in Table 3. Within the PYD-SF-PT total score (and its dimensions), the psychosocial variables (SR and RES) and the Healthy Lifestyle Index was mainly observed a significant positive linear association, and a significant negative linear association with the psychosocial variable STAI-T.

Table 3. Pearson Correlation between the total score and its correspondent $5 \mathrm{C} /$ subscale dimensions of the PYD-SF-PT, the psychosocial variables and the Healthy Lifestyle Index

\begin{tabular}{|c|c|c|c|c|c|c|c|c|c|c|}
\hline $\begin{array}{l}\text { PYD-SF-PT, PSYCHOSOCIAL } \\
\text { VARIABLES AND HEALTHY } \\
\text { LIFE STYLE INDEX }^{1}\end{array}$ & 1 & 2 & 3 & 4 & 5 & 6 & 7 & 8 & 9 & 10 \\
\hline 1. PYD-CONFIDENCE & ------- & & & & & & & & & \\
\hline 2. PYD-COMPETENCE & $0.810^{*}$ & ------- & & & & & & & & \\
\hline 3. PYD-CONNECTION & $0.242 *$ & $0.202 *$ & ------- & & & & & & & \\
\hline 4. PYD-CARING & 0.028 & $0.077 *$ & $0.158^{*}$ & ------- & & & & & & \\
\hline 5. PYD-CHARACTER & -0.018 & -0.002 & $0.181 *$ & $0.408 *$ & ------- & & & & & \\
\hline 6. PYD-TOTAL SCORE & $0.743 *$ & $0.747 *$ & $0.577^{*}$ & $0.483 *$ & $0.463^{*}$ & ------- & & & & \\
\hline 7. HLIndex ${ }^{1}$ & $0.098^{*}$ & $0.060^{*}$ & $0.218^{*}$ & -0.022 & $0.078^{*}$ & $0.144^{*}$ & ------- & & & \\
\hline 8. SR & $0.198^{*}$ & $0.182 *$ & $0.360^{*}$ & $0.162 *$ & $0.217^{*}$ & $0.363 *$ & $0.268^{*}$ & ------- & & \\
\hline 9. RES & $0.176^{*}$ & $0.192 *$ & $0.360^{*}$ & $0.245^{*}$ & $0.249^{*}$ & $0.391 *$ & $0.135^{*}$ & $0.436^{*}$ & ------ & \\
\hline 10. STAI-T & $-0.291 *$ & $-0.215^{*}$ & $-0.458^{*}$ & 0.029 & $-0.068^{*}$ & $-0.343^{*}$ & $-0.279 *$ & $-0.463^{*}$ & -0.369 & -- \\
\hline
\end{tabular}

PYD-SF-PT: Positive Youth Development-Short Form, Portuguese reduced Version; RES: Resilience; SR: Self-regulation; STAI-T: State-Trait Anxiety Inventory, Trait.

${ }^{1}$ The Healthy lifestyle Index was created using the combination of seven behaviour and participants scored one point for achieving each of the following lifestyle categories: a) having breakfast 7 days/week; b) sleeping hours $\geq 7$ hours; c) not smoking; d) not consuming drugs; e) not getting drunk; f) not having intense worries; g) not being bored at school.

* Correlation is significant at the 0.01 level. 
Table 4 shows the results of the linear regression analysis for Healthy Life Style Index and PYD-SF-PT (Total Score) and psychosocial variables in Portuguese youths, adjusted by age and gender (Step 1 and Step 2). In step 1, a model was achieved for Healthy Lifestyle Index $\left[\mathrm{F}(2,2662)=36.813, \mathrm{p}<0.001, \mathrm{R}^{2}=.039\right]$. The PYD-SF-PT had a significantly association: the youths who had higher PYD-SF-PT tended to have a higher Healthy Lifestyle Index behaviours. In step 2, a model was also achieved for Healthy Lifestyle Index $[\mathrm{F}(6,2658)=58.751, \mathrm{p}<0.001$, $\left.\mathrm{R}^{2}=.115\right]$. The psychosocial variables SR and STAI-T had a significantly association: the youths who had higher self-regulation and lower anxiety were more likely to have higher score of Healthy Lifestyle Index behaviours. In this step 2, PYD-SF-PT had no longer a significantly association and no associations were found for RES.

Table 4. Summary of linear regression results for Healthy Life Style Index and PYD-SF-PT (Total Score) and psychosocial variables in Portuguese youths, adjusted by age and gender (Step 1 and Step 2)

\begin{tabular}{|c|c|c|c|c|c|c|c|c|}
\hline & \multicolumn{4}{|c|}{$\begin{array}{l}\text { Model } 1 \\
\text { (Step } 1 \text { - PYD-SF) }\end{array}$} & \multicolumn{4}{|c|}{ (Step 2 - Psychosocial Variables) } \\
\hline & Variables & $B$ & $S E B$ & $\beta$ & Variables & $B$ & $S E B$ & $\beta$ \\
\hline & PYD-SF-PT & 0.022 & 0.003 & $0.139 * * *$ & PYD-SF-PT & 0.003 & 0.003 & 0.019 \\
\hline HEALTHY LIFE & & & & & SR & 0.013 & 0.002 & $0.165 * * *$ \\
\hline \multirow[t]{4}{*}{ STYLE INDEX } & & & & & RES & -0.005 & 0.004 & -0.029 \\
\hline & & & & & STAI-T & -0.032 & 0.003 & $-0.203 * * *$ \\
\hline & $R^{2}$ & & & .039 & $R^{2}$ & & & 0.115 \\
\hline & $F$ & & & $36.813^{* * *}$ & $F$ & & & $58.751 * * *$ \\
\hline
\end{tabular}

Note. $B$ (unstandardized coefficient) and $S E$ (standard error); $\beta$ : standardized coefficients.

$* * * \mathrm{p} \leq .001 ; * * \mathrm{p} \leq .01 ;{ }^{*} \mathrm{p} \leq .05$

Analyses were adjusted for age and gender.

PYD-SF-PT: Positive Youth Development-Short Form, Portuguese reduced Version; RES: Resilience; SR: Self-regulation; STAI-T: State-Trait Anxiety Inventory, Trait.

\section{Discussion}

The purpose of this paper was to examine the correlation between PYD, a composite of Healthy Lifestyle Behaviours and Psychosocial variables (self-regulation, resilience and anxiety), and, the impact of PYD and psychosocial variables in Healthy Lifestyle behaviours. A brief overlook of the results showed that most of the variables in this study have significantly correlational associations. Thus, it seems that positive youth development, resilience, self-regulation and healthy behaviours are connected, interacting in a positive correlational way, whereas anxiety in a negative direction. This results are in line with the idea in the literature that health behaviours tend to cluster together (Suris et al., 2008; DuRant, Smith, Kreiter \& Krowchuk, 1999; Rhee, Yun \& Khang, 2007), and that behaviours are crucial determinants to improve health outcomes (CDC, 2009; ECDA, 2012; WHO, 2013a).

Specifically, when analyzing the individual impact of the study variables, positive youth development had a significant association with healthy lifestyles behaviours (step 1). Interestingly, when combining the positive youth development with the psychosocial variables, (resilience, self-regulation and anxiety), a significant association with a higher value of explained variance was obtained (11.5\%) (step 2). Positive youth development was no longer significant and the psychosocial variables, namely self-regulation and anxiety had a significant association with healthy lifestyle behaviours. These findings are in accordance with literature, that pointed out the relevance of strength-approaches (as the PYD) and psychosocial factors for health outcomes (Benson, Scales, Hamilton, \& Sesma, 2006; Kojima et al., 2009; Lerner et al., 2005; Small \& Memmo, 2004). Such results suggest a dynamic interdependence between all the variables in the study, positive youth development, self-regulation, resilience, anxiety and healthy lifestyle behaviours. More specifically, the linear regression model puts in evidence that the promotion of positive youth development and self-regulation, along with the reduction of anxiety can have a relevant impact for improving healthy lifestyle behaviours. In addition, these findings reinforce the need to continue to study positive indicators, and to strengthen internal and external developmental assets (Catalano, Berglund, Ryan, Lonczak, \& Hawkins, 2004; Small \& Memmo, 2004), as it is suggested in the literature for the last two decades (Lippman, Moore, \& McIntosh, 2011). The present results are, as well, in line with more recent health 
recommendations, namely the need to include psychosocial factors in complement of health indicators (WHO, 2013b; Watson, 2014).

Additionally, the evidence of these findings may suggest that to increase the adoption of healthy behaviours it is also need to strengthen positive youth development and psychosocial variables, pointing out interventions that can put together a more holistic and integrative perspective, within an interdisciplinary and transdisciplinary work.

It is aimed that to increase the knowledge on these areas could help to prevent youth problems and risk behaviours, as well as to promote healthy development in a more effective way. Furthermore, identifying positive indicators, such as positive youth development and psychosocial variables, can give potentially useful suggestions for health professionals, educators and policy-makers, to better plan interventions and policies, to improve an integral perspective for healthy youths.

This study shows some limitations and the results need to be interpreted with the following issues in mind. Recall bias might be introduced through self-report, and some youths may be under-represented, due to the group's heterogeneity. So far, there is no consensus regarding how to define a healthy lifestyle in Europe, and the authors chose the best options available, taking into account the cutting-off points of the international guidelines. The cross-sectional design of the study precludes inferences concerning causality and longitudinal data would be needed. However, the present study has numerous strengths, namely including self-reports from a large sample of youths and with well-developmentally appropriate measures, based on both international projects, namely the Positive Youth Development cross-national project and the international survey Health Behaviour in School-aged Children (HBSC/WHO), in its extension to Portuguese Universities (HBSC/JUnP). In addition, it brings novelty by combining several relevant variables for a healthy development such as psychosocial variables, positive youth development and a composite score for healthy lifestyle behaviours. In future research it would be relevant to replicate these variables in specific populations and to include other clinical/psychosocial variables, aiming to increase the knowledge of such interactions.

\section{Conclusion}

The present research reinforces the recommendations in the literature that stressed out the relevance of studying positive indicators for youth development. Additionally, it stresses out the potential protective factors for a healthy youth development, such as the dynamic interdependence between positive youth development, self-regulation, resilience, anxiety and healthy lifestyle behaviours. To have more knowledge in these area can be important for health professionals, educators and policy-makers, to better plan interventions and policies, to improve an integral and holistic perspective for healthy youths, based on interdisciplinary and transdisciplinary work.

\section{Acknowledgements}

A special thanks to all the universities, students, teachers and experts who participated in this study. To National experts for their collaboration in revising the methodology and the used instruments. To the HBSC/WHO network (www.hbsc.org) whose survey was partially used for this purpose. To Nora Wiium and the other colleagues from PYD international: http://www.uib.no/en/rg/sipa/pydcrossnational for all support and inspiration.

\section{Competing Interests Statement}

The authors declare that they have no competing or potential conflicts of interest.

\section{References}

Benson, P. L., Leffert, N., Scales, P. C., \& Blyth, D. A. (1998). Beyond the village rhetoric: Creating healthy communities for children and adolescents. Applied Developmental Science, 2, 138-159. https://doi.org/10.1207/s1532480xads0203_3

Benson, P. L., Scales, P. C., Hamilton, S. F., \& Sesma, A. (2006). Positive youth development: Theory, research and application. In W. Damon \& R. M. Lerner (Eds.), Handbook of child psychology (pp. 894-941). New York: Wiley.

Bowers, E. P., Li, Y., Kiely, M. K., Brittian, A., Lerner, J. V., \& Lerner, R. M. (2010). The Five Cs model of positive youth development: a longitudinal analysis of confirmatory factor structure and measurement invariance. J Youth Adolesc, 39(7), 720-735. https://doi.org/10.1007/s10964-010-9530-9

Brownson, R. C., Remington, P. L., \& Wegner, M. V. (2010). Chronic disease epidemiology and control. Washington, DC: American Public Health Association.

Busseri, M. A., \& Rose-Krasnor, L. (2009). Breadth and intensity: salient, separable, and developmentally significant dimensions of structured youth activity involvement. British Journal of Development Psychology, 27(Pt 4), 907-933. https://doi.org/10.1348/026151008X397017

Cable, N., Chandola, T., Aida, J., Sekine, M., \& Netuveli, G. (2017). Can sleep disturbance influence changes in 
mental health status? Longitudinal research evidence from ageing studies in England and Japan. Sleep Medicine, 30, 216-221. https://doi.org/10.1016/j.sleep.2016.11.017

CDC. (2009). The power of prevention. Chronic disease ... the public health challenge of the 21st century. Atlanta, GA: Centers for Disease Control and Prevention.

Catalano, R. F., Berglund, M. L., Ryan, J. A. M., Lonczak, H. S., \& Hawkins, J. D. (2004). Positive youth development in the United States: Research findings on evaluations of positive youth development programs. Annals of the American Academy of Political and Social Science, 591, 98-124. https://doi.org/10.1177/0002716203260102

Constantine, N.A., \& Benard, B. (2001). California Healthy Kids Survey Resilience Assessment Module: Technical Report. Berkeley, CA: Public Health Institute.

Constantine, N.A., Benard, B., \& Diaz, M. (1999). Measuring Protective Factors and Resilience Traits in Youth: The Healthy Kids Resilience Assessment. Paper presented at the Seventh Annual Meeting of the Society for Prevention Research, New Orleans, LA.

Conway, R., Heary, C., \& Hogan, M. (2015). An evaluation of the measurement properties of the Five Cs model of Positive Youth Development. Frontiers in Psychology, 6, 1941. https://doi.org/10.3389/fpsyg.2015.01941

Dias, P., Castillo, J.A., \& Moilanen, K. (2014). The Adolescent Self-Regulatory Inventory (ASRI) Adaptation to Portuguese Context. Paidéia, 24(58), 155.163. https://doi.org/10.1590/1982-43272458201403

DuRant, R.H., Smith, J.A., Kreiter, S.R., Krowchuk, D.P. (1999). The relationship between early age of onset of initial substance use and engaging in multiple health risk behaviors among young adolescents. Archives of Pediatrics \& Adolescent Medicine, 153, 286-91. https://doi.org/10.1001/archpedi.153.3.286

ECDA. (2012). Optimising the response to the epidemic of chronic diseases. European Chronic Disease Alliance input to the reflection process on chronic diseases: European Chronic Disease Alliance.

Erickson, E. (1982). The Life Cycle Completed. New York: Norton.

Geldhof, G. J., Bowers, E. P., Boyd, M. J., Mueller, M. K., Napolitano, C. M., Schmid, K. L., . . Lerner, R. M. (2014). Creation of short and very short measures of the five Cs of positive youth development. Journal of Research on Adolescence, 24(1), 163-176. https://doi.org/10.1111/jora.12039

Grandner, M. A., Hale, L., Moore, M., \& Patel, N. P. (2010). Mortality associated with short sleep duration: The evidence, the possible mechanisms, and the future. Sleep Medicine Reviews, 14(3), 191-203. https://doi.org/10.1016/j.smrv.2009.07.006

Jelicic, H., Bobek, D. L., Phelps, E., Lerner, R. M., \& Lerner, J. V. (2007). Using positive youth development to predict contribution and risk behaviors in early adolescence: Findings from the first two waves of the 4-H study of positive youth development. International Journal of Behavioral Development, 31(3), 263-273. https://doi.org/10.1177/0165025407076439

Kojima, M., Kojima, T., Ishiguro, N., Oguchi, T., Oba, M., Tsuchiya, H., Sugira, F., Furukawa, T., Suzuki, S., \& Tokudome, S. (2009). Psychosocial factors, disease status, and quality of life in patients with rheumatoid arthritis. Journal of Psychosomatic Research, 67, 425-431. https://doi.org/10.1016/j.jpsychores.2009.01.001

Lerner, J. V., Bowers, E. P., Minor, K., Boyd, M. J., Mueller, M. K., Schmid, K. L., . . Lerner, R. M. (2013). Positive youth development: processes, philosophies, and programs. In R. M. Lerner, M. A. Easterbrooks \& J. Mistry (Eds.), Handbook of psychology: Developmental Psychology (Vol. 6, pp. 365-392). Hoboken, NJ: Wiley.

Lerner, R. M., Lerner, J. V., Almerigi, J. B., Theokas, C., Phelps, E., Gestsdottir, S., . . . von Eye, A. (2005). Positive Youth Development, participation in community youth development programs, and community contributions of fifth-grade adolescents: Findings from the first wave of the 4-H study of positive youth development. Journal of Early Adolescence, 25(1), 17-71. https://doi.org/10.1177/0272431604272461

Lerner, R. M., Lerner, J. V., Lewin-Bizan, S., Bowers, E. P., Boyd, M., Mueller, M., . . Napolitano, C. (2011). Positive youth development: Processes, programs, and problematics. Journal of Youth Development, 6(3), 40-64. https://doi.org/10.5195/JYD.2011.174

Lippman, L. H., Moore, K. A., \& McIntosh, H. (2011). Positive Indicators of Child Well-Being: A Conceptual Framework, Measures, and Methodological Issues. Applied Research in Quality of Life, 6(4), 425-449. https://doi.org/10.1007/s11482-011-9138-6

Loef, M., \& Walach, H. (2012). The combined effects of healthy lifestyle behaviors on all cause mortality: a systematic review and meta-analysis. Preventive Medicine, 55(3), 163-170. 
https://doi.org/10.1016/j.ypmed.2012.06.017

Martins, M. H. (2007). Resiliência: para além da diversidade e do risco. [Resilience: beyond diversity and risk]. Actas do II Congresso Família, Saúde e Doença, Modelos, Investigação e Prática em diversos contextos de Saúde. Universidade do Minho: Braga.

Matos, M. G., \& Equipa Aventura Social. (2000-2014). Aventura Social \& Saúde, A saúde dos adolescentes portugueses - Relatórios Nacionais do Estudo HBSC 2000, 2002, 2006, 2010, 2014 [Social Adventure \& Health: Portuguese Adolescents's Health - Final report from HBSC 2000, 2002, 2006, 2010, 2014 Study]. Lisboa: Centro Malária e Outras Doenças Tropicais/IHMT/UNL, FMH/UTL.

Matos, M. G., Santos, T., \& Reis, M. (2017). BePositive project: Positive Youth Development (PYD) in adolescents. Portuguese report. Saarbrucken: Lambert Academic Publishing.

Moilanen, K. L. (2007). The Adolescent Self-Regulatory Inventory: The development and validation of a questionnaire of short-term and long-term self-regulation. Journal of Youth and Adolescence, 36, 835-848. https://doi.org/10.1007/s10964-006-9107-9

Rhee, D., Yun, S. C., \& Khang, Y. H. (2007). Co-occurrence of problem behaviors in South Korean adolescents: findings from Korea Youth Panel Survey. Journal of Adolescent Health, 40, 195-7. https://doi.org/10.1016/j.jadohealth.2006.08.007

Silva, D., \& Spielberger, C. D. (2007). Manual do Inventario de Estado-Traço de Ansiedade (STAI), [Manual for the State-Trait Anxiety Inventory]. Consulting Psychologists Press, Inc.

Simões, C., Matos, M. G., \& Equipa do Projecto Aventura Social. (2012). Risk behaviors in Adolescents with Special Needs: Are Social and Emotional Competences Important?. Procedia - Social and Behavioral Sciences, 69, 2219-2227. https://doi.org/10.1016/j.sbspro.2012.12.191

Simões, C., Matos, M.G., \& Morgan, A. (2015). Facing the adversity: The role of internal assets on well-being in adolescents with special needs. Spanish Journal of Psychology, 18(e56), 1-14. https://doi.org/10.1017/sjp.2015.41

Small, S., \& Memmo, M. (2004). Contemporary models of youth development and problem prevention: Toward an integration of terms, concepts, and models. Family Relations, 53(1), 3-11. https://doi.org/10.1111/j.1741-3729.2004.00002.x

Spielberger, C., Gorsuch, R., \& Lushene, R. (1970). Manual for state-trait Anxiety Inventory. Palo Alto, CA: Consulting Psychologists Press.

Suris, J.C., Michaud, P.A., Akre, C., Sawyer, S.M. (2008). Health risk behaviors in adolescents with chronic conditions. Pediatrics, 122, e1113-8. https://doi.org/10.1542/peds.2008-1479

Watson, A. (2014). Psychosocial support for children and families requiring renal replacement therapy. Pediatric Nephrology, 29, 1169-1174. https://doi.org/10.1007/s00467-013-2582-9

WHO. (2005). Preventing chronic diseases: a vital investment: WHO global report. Geneva: World Health Organization.

WHO. (2013a). Global action plan for the prevention and control of noncommunicable diseases 2013-2020. Geneva: World Health Organization.

WHO - World Health Organization (2013b). Health 2020: A European Policy Framework and Strategy for the 21 st Century. Geneva, Switzerland: World Health Organization.

WHO. (2014). Noncommunicable diseases country profiles 2014. Geneva: World Health Organization.

WMA - World Medical Association. (2008). World medical association declaration of Helsinki: Ethical principles for medical research involving human subjects. Retrieved from http://www.wma.net/en/20activities/10ethics/10helsinki/

\section{Copyrights}

Copyright for this article is retained by the author(s), with first publication rights granted to the journal.

This is an open-access article distributed under the terms and conditions of the Creative Commons Attribution license (http://creativecommons.org/licenses/by/4.0/). 